\title{
Kesempatan Perempuan mendapatkan Pelayanan dan Hak Kesehatan Reproduksi di Pedesaan Alor, Nusa Tenggara Timur
}

\section{Sipin Putra}

Universitas Indonesia

Abstrak: Provinsi Nusa Tenggara Timur (NTT) sejak dulu dianggap sebagai daerah di mana angka kematian ibu dan anak yang tinggi di Indonesia. Di saat yang bersamaan, Millennium Development Goals (MDGs) dari Perserikatan Bangsa-Bangsa (PBB) menyerukan terhadap semua negara dalam hal pengurangan substansial dalam kematian anak dan ibu hingga tahun 2015 (dari 1990). Karena itu, Indonesia dan NTT perlu memiliki program komitmen yang kuat. Mengurangi kematian ibu dan anak adalah salah satu dari program strategis Kementerian Kesehatan 2015-2019. Indonesia masih mengalami permasalahan kematian ibu tinggi, kasus HIV, status gizi buruk dan penyakit tidak menular. Presiden Joko Widodo menyatakan pentingnya meningkatkan kesehatan dan kesejahteraan ibu agar kesehatan anak lebih baik, hal ini menjadi bagian dari program prioritas nasional. Penelitian ini bertujuan untuk memberikan bukti berdasarkan peluang dan partisipasi perempuan dalam hak dan layanan kesehatan reproduksi. Penelitian ini juga mengidentifikasi pengucilan sosial di antara keputusan perempuan yang berkaitan dengan praktik tradisional dan budaya; untuk mengeksplorasi kebijakan kesehatan reproduksi di Alor. Peneliti mengambil informasi dari Dinas Kesehatan Provinsi dan Kabuaten Alor dengan menggunakan wawancara mendalam dan diskusi kelompok. Hasil penelitian menunjukkan bahwa pendidikan kesehatan reproduksi terbatas khususnya untuk perempuan. Konsultasi pra nikah adalah salah satu kebijakan dari Badan Kependudukan dan Keluarga Berencana (BKKBN) dan Kementerian Agama dari tingkat pusat hingga kecamatan. Kekerasan berbasis gender biasanya terjadi terkait aktivitas seksual perempuan dan laki-laki. Posisi perempuan dalam komunitas masih lemah, terutama yang terkait dengan budaya mas kawin 'belis' - Moko. Belis menjadi sebuah belenggu bagi Perempuan Alor dalam mengakses hak dan kesehatan reproduksi. Perempuan Alor belum paham benar tentang hak kesehatan reproduksi mereka.

Kata Kunci: Perempuan, Hak Kesehatan Reproduksi, FGD, Belis

Abstract: East Nusa Tenggara has traditionally been considered as one of the regions where maternal and child mortality is high. At the same time, UN MDGs call all countries for substantial reductions in child and maternal mortality by three-quarters by 2015 (from 1990 levels). Accordingly, Indonesia and NTT need to have a strong commitment program. Reducing maternal and child deaths are one of the 2015-2019 Ministry of Health strategic programs. Mothers are still experiencing high maternal deaths, HIV cases, poor nutrition status and noncommunicable diseases. President Joko Widodo stated the importance for 
improving mothers' health and wellbeing to influence better early-age health outcomes which also part of the national priority. This study aims to deliver evidence-based on women's opportunity and participation in reproductive health rights and services that would assist the Ministry of Health to achieve universal access in their life and equal rights. And to identify social exclusion among women decisions in relation with traditional practices and cultural beliefs; to explore reproductive health policies in Alor. Our team is placed to take this forward from the provincial health office, District health office of Alor which are also being explored by using in-depth interview, fgd and group interview. The results showed that limited reproductive health education. Pre-marriage consultation is one policy from the central level to sub district. Gender based violence commonly occur relating sex activity. Women's position in the community is still weak, especially related to the 'belis' dowry culture-Moko. Women in Alor are not aware yet about their reproductive health rights.

Key Words: Women, Reproductive Health Rights, FGD, Belis

Korespondensi Penulis:

Sipin Putra, Departemen Antropologi, Universitas Indonesia.

E-mail: sipin.putra@gmail.com

\section{PENDAHULUAN}

Permasalahan mengenai akses perempuan terhadap pelayanan kesehatan reproduksi di pedesaan Kabupaten Alor tidak bisa dilepaskan dari konteks sosial budaya masyarakatnya. Dalam sistem patriarki perempuan tergantung pada laki-laki untuk hal pengambilan keputusan untuk mengakses pelayanan kesehatan reproduksi. Fasilitas kesehatan sudah banyak di sekitar tempat tinggal mereka. Akses terhadap fasilitas kesehatan pun dapat dikatakan cukup mudah karena sarana transportasi sudah tersedia. Namun, hal apa saja yang menjadi hambatan utama yang harus dihadapi oleh perempuan dalam mengakses haknya. Faktor budaya lokal dan ikatan perkawinan yang mengharuskan dengan membayar belis (mas kawin) menjadi salah satu penyebab para perempuan terhambat dalam mendapatkan pelayanan dan hak kesehatan reproduksi.

Alor merupakan kabupaten yang berada di Provinsi Nusa Tenggara Timur. Kabupaten Alor berupa kepulauan yang terdiri dari 17 kecamatan dan terbagi dalam 175 desa/kelurahan Akses utama menuju Kabupaten Alor yaitu pesawat terbang dari Kota Kupang. Selain itu juga terdapat kapal Angkutan Sungai dan Penyeberangan (ASDP) yang berlayar setiap hari. Kapal ASDP ini melayani pelabuhan Kupang ke Pelabuhan di Kalabahi, ibukota Kabupaten Alor. Jumlah penduduk di Kabupaten Alor pada tahun 2017 
yaitu 201.515 jiwa yang terdiri dari 98.275 laki laki dan 103.240 perempuan. Dengan demikian, rasio jenis kelamin mencapai 95.19 \%. Kabupaten Alor akan terus berkembang dengan potensi ekonomi hasil perkebunan dan juga hasil tenun yang menjadi ciri khas kabupaten ini.

Menurut data Badan Pusat Statistik (BPS), ada 11 kematian bayi dari jumlah 4.799 kelahiran pada tahun 2017. Selama ini khususnya ibu hamil, untuk kunjungan K1 mencapai 96 \% sedangkan kunjungan K4 mencapai 91.68 \%. K1 merupakan kunjungan pertama (ke 1) di mana usia kehamilan antara 1-3 bulan. Selama tahun 2017 untuk pelayanan persalinan dibantu tenaga kesehatan mencapai $84.27 \%$. Hal ini dapat dikatakan bahwa masyarakat Alor khususnya perempuan sudah dapat mengakses fasilitas kesehatan. Dapat pula dikatakan tenaga kesehatan ada di sekitar tempat tinggal masyarakat. Masyarakat sebenarnya mempunyai kesadaran dalam memperhatikan kesehatan diri dan lingkungannya. Masyarakat Alor tergolong aktif untuk mendapatkan pelayanan kesehatan. Namun di sisi lain, mereka belum terpapar informasi mengenai pengetahuan kesehatan reproduksi dan hak mereka, terutama perempuan. Mereka hanya terlihat aktif mendukung setiap program atau kegiatan yang diadakan oleh pemerintah daerah maupun pusat terutama program di bidang kesehatan. Sebagai buktinya, program KB sangat sukses di Kabupaten Alor. Untuk alat kontrasepsi, data menunjukkan selama tahun 2017 jumlah peserta KB Aktif 48.38 \%. Namun Angka Kematian Ibu (AKI) yang dilaporkan masih 250 per 100.000 kelahiran hidup. Hal ini menjadi menarik untuk melakukan kajian lebih mendalam mengenai kesehatan reproduksi perempuan di Alor.

\section{TINJAUAN PUSTAKA}

Indonesia dan banyak negara Asia sejak dahulu menerapkan budaya dominan laki-laki, di mana perempuan sering diposisikan di kelas sosial kedua dan dalam kekuatan tawar yang lebih lemah dalam pengambilan keputusan keluarga, termasuk dalam keputusan terkait kesehatan. Di Indonesia Timur, misalnya, adat istiadat setempat dan tradisi keluarga sangat memengaruhi perilaku ibu ketika menyangkut kesehatan anak-anak mereka (Hull et al., 2006; Pardosi et al., 2014; Prasodjo et al., 2015). Menurut Survei Kesehatan dan Survei Demografi Indonesia (SDKI) 2007 dan 2012, kurangnya pengetahuan kesehatan reproduksi di kalangan perempuan kemungkinan terkait dengan risiko tinggi kematian bayi dan anak. Satu dari dua wanita pedesaan $(51,3 \%)$ tidak 
menerima informasi tentang komplikasi kehamilan mereka selama perawatan antenatal. Selain itu, ada 52,4\% pengiriman rumah terjadi di daerah pedesaan yang dipengaruhi oleh keputusan suami mereka dan kesulitan dalam mengakses layanan kesehatan (Statistics Indonesia 2008; 2013). Studi dalam populasi yang kurang beruntung secara ekonomi menunjukkan bahwa meningkatkan pendidikan wanita dan memberdayakan mereka dalam pengambilan keputusan yang mencari kesehatan telah secara signifikan mengurangi kematian anak usia dini dan meningkatkan kesehatan anak (Becker et al. 2006; Fantahun et al. 2007; Senarath \& Gunawardena 2009). Salah satu solusi adalah implementasi kebijakan untuk meningkatkan kesetaraan dan persalinan wanita termasuk partisipasi mereka terhadap hak kesehatan reproduksi (Thomsen et al. 2011). Oleh karena itu, pendekatan ini juga perlu dilakukan di Indonesia khususnya di daerah pedesaan.

Namun, pertanyaannya masih tetap mengapa perempuan pedesaan masih mengalami pengucilan sosial dalam mencapai hak kesehatan reproduksi mereka meskipun upaya telah dilakukan oleh pemerintah dan berbagai lembaga; dan juga, bagaimana pemerintah harus bertujuan untuk mempromosikan kesetaraan perempuan dalam hal hak dan kebutuhan kesehatan reproduksi perempuan. Oleh karena itu, penelitian ini bertujuan untuk mengatasi kesenjangan penelitian ini untuk perempuan di daerah pedesaan di Indonesia Timur. Hasil utama dari penelitian ini adalah arahan bagi pemerintah tentang bagaimana meningkatkan partisipasi perempuan dalam kaitannya dengan kehamilan dan persalinan yang juga mencakup kebutuhan kesehatan reproduksi dan layanan yang relevan. Kebijakan semacam itu bertujuan meningkatkan peran ibu dalam pengambilan keputusan perawatan kesehatan akan membantu meningkatkan hasil persalinan dan kesehatan bayi. Dalam hal relevansi kebijakan, perempuan telah menjadi fokus strategis Presiden Joko Widodo sesuai dengan Visi Presiden 2019 untuk mencapai "realisasi Indonesia yang makmur, demokratis dan adil". Mengurangi kematian ibu dan anak adalah salah satu dari program strategis Kementerian Kesehatan Indonesia 2015-2019. Ibu masih mengalami kematian ibu yang tinggi, kasus HIV/AIDS, status gizi buruk dan penyakit tidak menular (mis. Diabetes dan hipertiroid). Selama pertemuan ICPD 2016 di Bali, Presiden Joko Widodo menyatakan pentingnya untuk meningkatkan kesehatan dan kesejahteraan ibu untuk mempengaruhi hasil kesehatan anak usia dini yang lebih baik yang juga merupakan bagian dari prioritas nasional dan program strategis Kementerian Kesehatan. Di forum global, Indonesia menerapkan Tujuan 
Pembangunan Berkelanjutan terutama mengurangi kematian ibu dan anak dan malnutrisi perempuan pada tahun 2030. Oleh karena itu, penelitian ini bertujuan untuk memberikan bukti berdasarkan peluang dan partisipasi perempuan dalam kebutuhan dan layanan kesehatan reproduksi yang akan membantu pemerintah Indonesia khususnya Kementerian Kesehatan (Kemenkes) dan Kementerian Pemberdayaan Perempuan dan Perlindungan Anak (KPPPA) untuk mencapai akses universal untuk meningkatkan status kesehatan reproduksi perempuan dalam kehidupan mereka dalam bentuk perawatan kontinum dan persamaan hak bagi setiap perempuan di Indonesia. Pendekatan kualitatif akan digunakan untuk mengeksplorasi secara lebih rinci tentang posisi perempuan dalam membuat keputusan kesehatan reproduksi dan partisipasi mereka dalam kaitannya dengan praktik tradisional dan kepercayaan budaya sebagai kontribusi utama yang berkaitan dengan konteks kesehatan reproduksi di negara berkembang dari perspektif dan pengalaman perempuan pedesaan.

\section{METODE DAN DATA}

Penelitian ini dilakukan pada periode Februari-April 2018. Proses pemilihan daerah dan pengambilan sampel ditentukan oleh pertanyaan penelitian tentang mengapa perempuan pedesaan masih mengalami pengucilan sosial dalam mencapai hak kesehatan reproduksi mereka meskipun upaya telah dilakukan oleh pemerintah dan berbagai lembaga. Oleh karena itu, pemilihan ini menggunakan pendekatan purposive sampling. Penelitian ini berfokus pada kabupaten Alor di provinsi NTT karena fakta bahwa wilayah ini masih didominasi oleh daerah pedesaan (yaitu 85\%). Selain itu, Kabupaten Alor masih memiliki banyak daerah terpencil di mana akses ke fasilitas kesehatan, terutama pada layanan dan perawatan kesehatan alat reproduksi, masih menjadi masalah utama.

Kami melakukan kajian terutama pada ketersediaan layanan kesehatan reproduksi, dua desa oleh puskesmas telah dipilih. Satu desa dengan puskesmas di mana layanan kesehatan reproduksi disediakan dan desa lain dengan puskesmas yang belum menyediakan layanan kesehatan reproduksi. Masalah lain seperti kepadatan populasi juga telah dimasukkan dalam proses seleksi ini. Untuk memilih responden kegiatan wawancara mendalam dan kelompok, metode snowball sampling akan diterapkan. Pemilihan responden dilakukan hanya untuk mereka yang memiliki pengalaman dalam masalah kesehatan reproduksi dan mampu memberikan wawasan berharga dalam tema 
penelitian ini. Ukuran sampel yang memadai dalam penelitian ini bergantung pada jumlah informasi yang akan dikumpulkan.

Penelitian ini dilakukan dengan menggunakan pendekatan kualitatif seperti wawancara mendalam, wawancara kelompok dan desk analysis dari pengumpulan data sekunder. Jenis data berupa rekaman hasil wawancara maupun diskusi akan ditranskripsi secara detail. Wawancara mendalam berlangsung lebih lama dari wawancara berbasis kuesioner. Para perempuan Alor didorong untuk berbicara lebih banyak mengenai satu masalah khusus daripada sekadar mengajukan pertanyaan dan segera pindah ke pertanyaan berikutnya. Metode ini berguna ketika informan relatif sedikit jumlahnya dan topik dieksplorasi lebih dalam. Fathalla dan Fathalla (2004) menunjukkan bahwa wawancara mendalam cocok untuk memahami persepsi informan mengenai masalah tertentu, di mana responden akan merasa nyaman untuk berbicara dan dapat mendefinisikan dengan baik.

Keuntungan dengan metode wawancara mendalam adalah petunjuk non-verbal seperti suara dan ekspresi wajah juga dapat membantu dalam proses analisa. Peneliti juga bijaksana dan terlatih untuk memahami ekspresi verbal selama wawancara berlangsung.

Mempertimbangkan semua metode pengumpulan data yang di atas, maka tujuan dari penelitian ini adalah untuk memeriksa peluang dan partisipasi perempuan dalam layanan kesehatan reproduksi di pedesaan Alor, NTT. Selain itu penelitian ini mengidentifikasi pengucilan sosial di antara perempuan pada keputusan kesehatan reproduksi sehubungan dengan praktik tradisional dan kepercayaan budaya di pedesaan Alor, NTT. Data hasil penelitian ini juga dapat membantu dalam mengeksplorasi kebijakan kesehatan reproduksi yang kondusif untuk mempromosikan dan mempertahankan pemberdayaan perempuan dalam hak-hak kesehatan reproduksi di pedesaan Alor, NTT.

Instrumen penelitian yang akan digunakan antara lain, (1) pedoman wawancara mendalam, dan (2) pedoman wawancara kelompok. Semua dokumen untuk instrumeninstrumen ini mencakup formulir persetujuan yang diinformasikan dan panduan untuk diskusi kelompok dan wawancara mendalam. Panduan wawancara dan pertanyaan menyelidik akan digunakan untuk mengarahkan wawancara kepada informan terutama para perempuan di Pedesaan Alor. Pertanyaannya semi-terstruktur dan terbuka. Metode ini memberikan eksplorasi dan informasi luas mengenai topik terkait. Di sini, semua 
informan menjawab pertanyaan yang sama tetapi dengan cara mereka sendiri. Wawancara mendalam ini akan direkam audio yang kemudian ditranskripsi.

Sedangkan diskusi kelompok akan menggunakan panduan dan pertanyaan menyelidik yang akan digunakan selama proses diskusi berlangsung. Kelompok diskusi ini beranggotakan informan yang telah mengetahui masalah kesehatan reproduksi, praktik dan fasilitas kesehatan terkait dengan kesehatan reproduksi dalam dua tahun terakhir. Dalam hal ini, penting untuk memastikan bahwa peneliti harus dalam posisi netral. Selama wawancara, beberapa upaya juga penting untuk dilakukan, seperti memverifikasi tape recorder, apakah berfungsi dengan baik. Jika perlu, fasilitator akan membuat lebih banyak catatan tentang informasi terkait yang disebutkan oleh informan selama diskusi kelompok berlangsung.

\section{PEMBAHASAN}

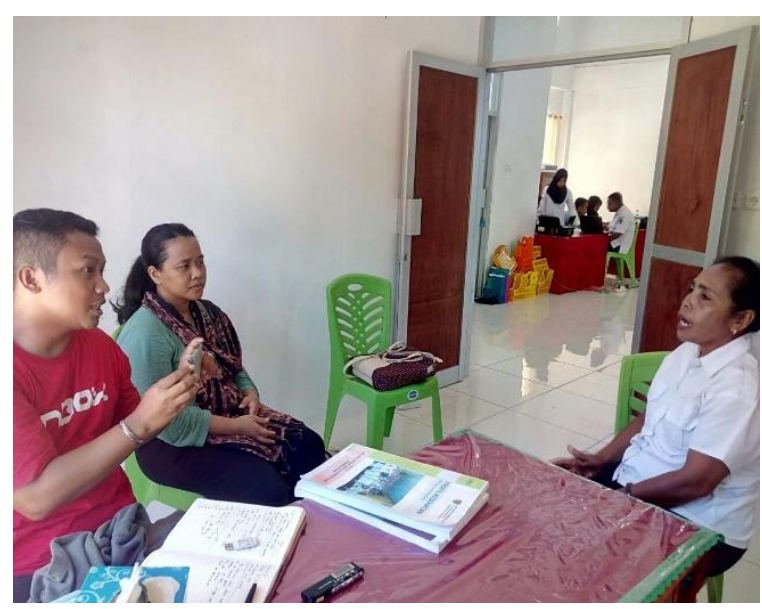

Sumber: Dokumentasi Peneliti, Maret 2018

Gambar 1. Wawancara dengan Kepala Puskesmas Kenarilang, Alor

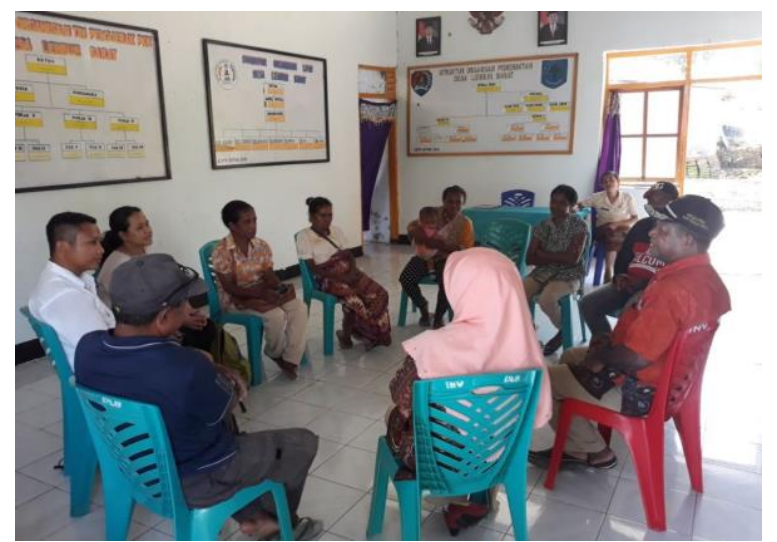

Sumber: Dokumentasi Peneliti, Maret 2018

Gambar 2. Proses Diskusi Kelompok yang difasilitasi Desa Adat Lembur Barat 
Sebagai seorang istri diharuskan mengabdi total kepada orang tua lelaki, tidak boleh kembali ke orang tua kandungnya. Saat ada masalah, si perempuan tidak boleh pulang ke orang tua kandungnya. Hal ini kemudian menjadi beban, hidup tidak bebas dan membuat perempuan merasa seperti disamakan dengan benda. Lalu, ketika keluarga perempuan meminta harga belis yang tinggi, sementara keluarga lelaki tidak ikhlas membayarkan atau tidak menyanggupi jumlah uang pembayaran dan berujung pada gagalnya pernikahan. Hal ini sering memicu pertikaian antar keluarga. Masalah ini bisa melebar ke berbagai hal dan berlarut-larut.

Oleh karena itu, masyarakat ingin keluar dari belenggu yang menjerat ini. Namun, budaya belis dengan moko adalah salah satu ciri identitas yang tak bisa diubah dari masyarakat Alor. Sudah mendarah daging dan menjadi bagian kehidupan yang penting. Permasalahan belis ini adalah salah satu faktor yang membuat orang Alor tetap miskin, tidak sekolah, tidak bisa baptis, tidak bisa menikah, bahkan membuat anak-anak muda sekarang juga sulit untuk menikah. Uang habis, sehingga anak-anak tidak bisa mendapatkan pendidikan berkualitas karena fokus hanya untuk moko.

Moko yang sudah menjadi benda pusaka memiliki peran penting dalam kehidupan masyarakat Alor. Fungsi moko yaitu sebagai sarana upacara, lambang status sosial, belis (sebutan untuk mas kawin di wilayah Indonesia timur), alat musik dan sebagai benda yang bernilai ekonomis (Gede, 1995: 76-78). Selain itu fungsi moko adalah sebagai lambang perdamaian dari pihak-pihakyang bertikai. Pada saat perdamaian dicapai salah satu pihak menyerahkan moko ke pihak lainnya sebagai simbol perdamaian, bahwa pertikaian telah berakhir. Moko yang telah digunakan sebagai lambang perdamaian ini tidak boleh digunakan lagi sebagai belis. Jika digunakan, dipercaya akan mendatangkan kemalangan bagi pasangan pengantin. Moko di Alor dijadikan sebagai mas kawin dalam adat perkawinan mereka (Bintarti dalam Gede, 1995: 72). Seseorang yang memiliki inisiatif untuk melaksanakan perkawinan harus memenuhi syarat yang terdiri dari: mas kawin (bride-price), pencurahan tenaga untuk kawin (bride-service), dan pertukaran gadis (bride-exchange) (Koentjaraningrat, 1980: 94). Dalam hal ini para pemuda yang ingin melamar gadis Alor dituntut untuk menyerahkan mas kawin berupa moko kepada keluarga si gadis.

Saat ini perkawinan antar suku sudah biasa terjadi di Alor. Seorang pemuda yang bukan etnis Alor yang berniat melamar gadis dari Alor juga harus memenuhi belis seperti yang diminta oleh keluarga gadis. Pemuda dari luar Kabupaten Alor bisa membeli 
moko atau jika diizinkan bisa diganti dengan sejumlah uang. Penggantian belis moko ke dalam bentuk uang juga diperbolehkan tidak hanya untuk pemuda luar Alor tapi juga untuk pemuda Alor yang kebetulan keluarganya tidak memiliki moko. Hal ini bisa diterima keluarga gadis yang pada umumnya berasal dari keluarga yang sudah modern atau bisa dikatakan berasal dari kalangan pegawai. Namun, masyarakat dari kalangan petani masih fanatik dan tidak mau menerima uang sebagai pengganti moko.

Moko yang diterima oleh keluarga sebagai belis atas anak gadisnya bisa saja dimanfaatkan kembali oleh anggota keluarganya yang lain untuk kembali meminang gadis. Beberapa keluarga memilih untuk tetap menyimpan moko mereka karena tidak ingin kebingungan untuk mendapatkan moko jika memiliki anak atau kerabat laki-laki yang akan menikah. Peredaran moko di Alor saat ini sangat dipengaruhiolehadatkawinmawin yang terjadi. Moko-moko yang beredar itu-itu saja (kecuali ada temuan baru), hanya kepemilikannya yang berpindah-pindah tangan mengingat moko adalah warisan turun temurun, tidak ada lagi moko yang diproduksi. walaupun moko diserahkan oleh keluarga laki-laki kepada keluarga perempuan ketika melamar, bukan berarti moko adalah alat pembayaran untuk membeli seorang gadis atau merupakan praktik penjualan manusia. Perempuan bukanlah 'properti' laki-laki. Perempuan yang sudah menjadi istri tidak diperlakukan dengan semena-mena oleh suami.

Perempuan juga mendapatkan kesulitan dalam mendapatkan akses untuk kesehatan reproduksi. Seorang istri, jika mendapatkan kekerasan dalam rumah tangga atau hak untuk menolak berhubungan badan dengan suami, tidak dapat dilaporkan kepada pihak berwenang seperti Kepolisian atau Dinas Pemberdayaan Perempuan karena masalah Kekerassan Dalam Rumah Tangga (KDRT) merupakan masalah rumah tangga yang dianggap tabu. Seorang perempuan membicarakan keburukan suami atau sebaliknya serta masalah rumah tangga lainnya menjadi tabu bahkan kepada orang tua sendiri.

Hasil Focus Group Discussion (FGD) menjelaskan bahwa jika seorang suami telah menikah dan telah membayar moko, namun sudah beberapa tahun menikah dan belum mempunyai anak sehingga pihak laki laki ini diperbolehkan untuk mencari istri lagi agar mempunyai keturunan. Pernikahan secara adat di masyarakat Alor tidak akan terwujud tanpa Moko. Tanpa pernikahan adat, tidak ada pernikahan secara agama. Tanpa pernikahan agama, sesuai peraturan, tidak ada pernikahan secara hukum. Ketika pernikahan secara sah sulit terlaksana, bagi pasangan yang tetap ingin bersatu maka 
bagi yang nekat akan hidup berkeluarga tanpa ikatan, atau "kumpul kebo". Rumah tangga tanpa ikatan legal akan berdampak pada anak-anak mereka yang tidak bisa memiliki akte kelahiran dan berkas administrasi lainnya. Padahal, akte kelahiran adalah hak anak untuk membentuk masa depannya, termasuk untuk melanjutkan pendidikan. Akibatnya sulit berkembang pendidikan di masyarakat setempat terutama yang diakses oleh perempuan. Ke depannya, si anak kesulitan menikah karena tak punya akte kelahiran atau karena orang tuanya belum menikah secara resmi.

\section{Implementasi Hak Reproduksi bagi Perempuan Alor}

Berkaitan dengan kebijakan mengenai kesehatan reproduksi, maka kita harus melihat kebijakan kesehatan reproduksi mulai dari tingkat pusat, provinsi kemudian kabupaten baru sampai dengan puskesmas yang akan menerapkannya di masyarakat. Di tingkat pusat sendiri, jika kita berbicara mengenai kesehatan reproduksi maka menurut Kepala sub bagian (Kasubbag) kesehatan reproduksi Kemenkes, menjelaskan hak reproduksi berhubungan dengan masalah mulai dari menstruasi di masa akhil balig, remaja sampai dengan masa lanjut usia. Namun jika kita bicara pada fase usia subur maka kita akan fokus pada usia antara 15-45 tahun menurut definisi World Health Organization (WHO).

Lebih lanjut dijelaskan bahwa kebijakan yang berkaitan dengan kesehatan reproduksi bagi sasaran usia subur adalah kebijakan berkaitan dengan "Calon Pengantin" (Catin). Catin dianggap penting dan krusial untuk diperhatikan, sebab catinlah yang nantinya akan menikah dan menghasilkan generasi penerus, seperti yang dikatakan informan:

“..calon pengantin perlu untuk diberi perhatian dari berbagai sisi terutama aspek kesehatan, sebab merekalah yang akan menikah lalu menghasilkan generasi penerus yang sehat dan baik. Jika Catin tidak diperhatikan maka nantinya dapat berdampak pada generasi yang tidak sehat bahkan berdampak ada kematian ibu dan bayinya" (Bu Re, Kemenkes di Jakarta, 12 Feb 2018)

Lebih lanjut dikatakan oleh informan dari Kemenkes Pusat, bagi Catin terdapat berbagai program mengenai kesehatan reproduksi, antara lain:

1. Kemenkes telah membuat KIA berupa lembar balik yang harus disampaikan oleh tenaga kesehatan. Program ini telah disampaikan hingga tingkat Provinsi 
2. Buku Kecil tentang Kesehatan Reproduksi untuk Catin. Berkaitan dengan program ini provinsi diberikan soft copy untuk kemudian dicetak dan diteruskan ke kabupaten/kota bahkan sampai puskesmas.

3. Sudah ada Petunjuk Teknis (Juknis) berkaitan dengan kesehatan reproduksi yang ditujukan pada tenaga kesehatan untuk melakukan advokasi ke calon pengantin.

4. Program community empowerment berupa pembuatan Buku Saku mengenai Kesehatan Reproduksi. Program ini bekerjasama dengan KUA melalui Kementerian Agama. Berkaitan dengan pentingnya masalah kesehatan reproduksi maka Kementerian Agama membuat suatu intervensi yang disebut "Kursus Catin". Dari sisi kesehatan, pada saat pemberian materi tentang kesehatan reproduksi maka yang akan menyampaikannya adalah tenaga kesehatan. Kursus ini menggunakan dana Bantuan Operasional Kesehatan (BOK). Informan di Kementerian kesehatan lebih lanjut mengharapkan melalui pendekatan dengan lintas sektor Kantor Urusan Agama (KUA) ini maka bisa dilakukan screening masalah kesehatan ibu dan anak dari awal. Rencananya pada tahun 2019 akan dibuat semacam "Kartu Sehat Catin”.

Lebih lanjut dijelaskan oleh informan dari tingkat pusat bahwa semua tenaga kesehatan dilatih tentang Tata Laksana Awal deteksi adanya kekerasan terhadap perempuan dan anak. Informan menjelaskan bahwa ranah dari Kementerian Kesehatan adalah "detect" dan "mengobati" sambal memberikan edukasi melalui Komunikasi, Informasi dan Edukasi (KIE). Untuk kekerasan ini leading sector nya adalah KPPPA dan P2TP2A, hal ini didukung dengan adanya tools assessment untuk deteksi awal kekerasan pada anak. Namun demikian P2TP2A hanya sampai tingkat kabupaten. Sedangkan info tentang kekerasan sudah tercantum juga di buku KIA, hal ini disebutkan oleh informan untuk upaya meningkatkan 'kesadaran' ibu-ibu di tingkat desa tentang kekerasan pada perempuan, sebab di tingkat Puskesmas pelayanan kesehatan terpadu di puskesmas ada di KIA. Sedangkan ranah BKKBN adalah pemberdayaan masyarakat mengenai Keluarga Berencana (KB).

Kementerian Kesehatan lebih kepada kebijakan serta manajemen tata laksana KB di fasilitas kesehatan dan saat bencana di mana ada ketentuan untuk adanya pelayanan minimum sehubungan dengan kesehatan reproduksi. Semua pedoman 
teknis itu bersifat universal untuk menjawab MDGs. Namun faktanya di pedesaan Alor, perempuan Alor tetap kurang mendapatkan sosialisasi mengenai hak dan pelayanan mereka mengenai kesehatan organ reproduksi. Mengenai organ reproduksi, perempuan Alor harus meminta ijin kepada para suaminya mengenai keputusan misalnya pemakaian alat kontrasepsi.

Adapun peraturan-peraturan yang berkaitan dengan Kesehatan Reproduksi dari Kementerian Kesehatan, antara lain:

- Permenkes No 92 tahun 2014 yang merupakan turunan dari PP No 61 tahun 2014, di mana Permenkes No 92 tahun 2014 menyatakan tentang prosedur pelayanan kesehatan Ibu Hamil, Ibu Bersalin, Ibu Nifas dan Keluarga Berencana.

- Permenkes No. 3 tahun 2016 yaitu tentang pelatihan tenaga kesehatan untuk menangani Aborsi akibat perkosaan dan indikasi medis.

- Permenkes No 68 tahun 2013 tentang masalah anak.

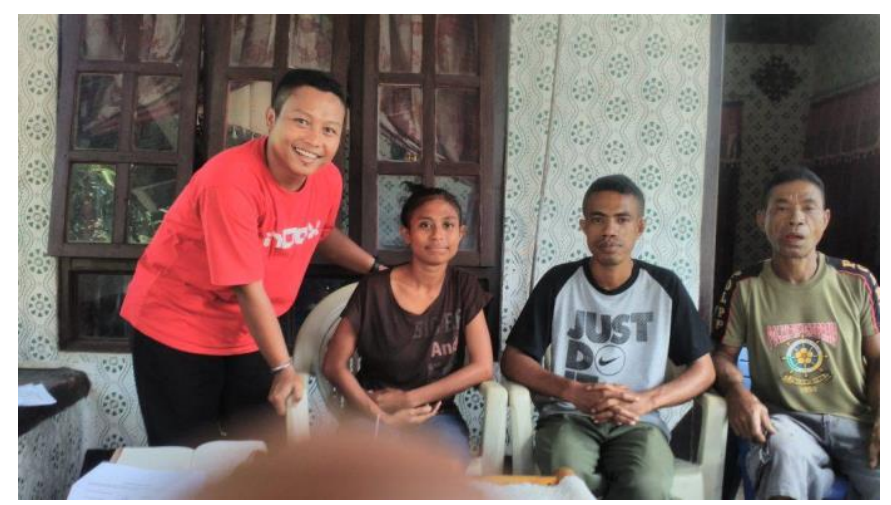

Sumber: Dokumentasi Peneliti

Gambar 3. Keluarga Informan di rumah pihak suami

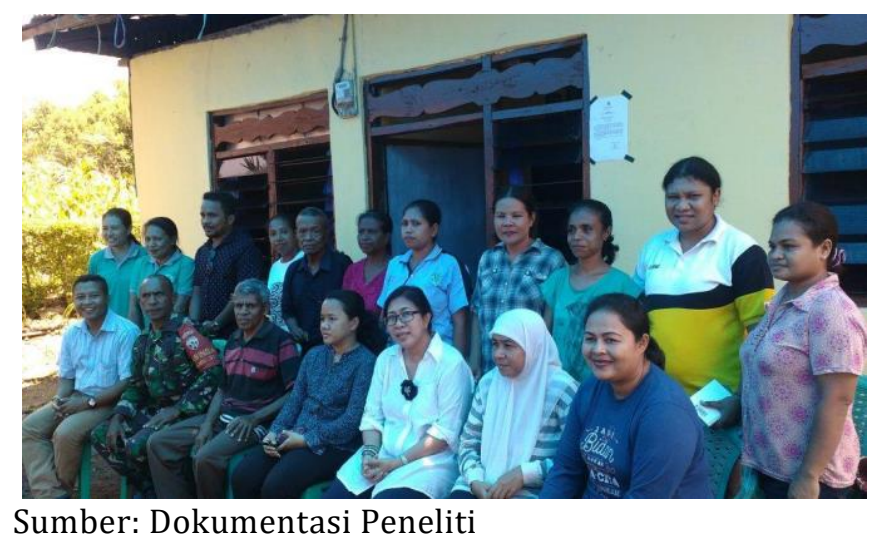

Gambar 4. Selepas diskusi di desa Kenarilang, Alor Tengah 
Perempuan di Kabupaten Alor merupakan orang yang dihormati dan dilindungi oleh masyarakat. Perempuan Alor dalam mendapatkan pengetahuan mengenai kesehatan reproduksi khususnya remaja di Kabupaten Alor masih memerlukan perhatian dari pemerintah baik pusat maupun daerah. Mereka kurang mendapatkan pengetahuan dalam hal pendidikan seks termasuk dalam pengetahuan kesehatan reproduksi. Institusi pendidikan baik formal (sekolah) maupun informal (bimbingan gereja) juga dirasa masih minim bagi masyarakat yang telah terpapar dengan kemajuan teknologi dan informasi. Jam bimbingan dan pengetahuan kesehatan reproduksi dari sekolah juga kurang. Hal ini karena pengetahuan kesehatan reproduksi ini hanya merupakan sebuah kegiatan informal yang termasuk dalam muatan lokal di sekolah. Selama ini tidak ada jam khusus yang menjelaskan kesehatan reproduksi di kelas-kelas.

Ekstrakurikuler kampus seperti Usaha Kesehatan Sekolah (UKS) hanya berfokus menangani siswa yang sakit selama kegiatan belajar mengajar di sekolah. Bagi yang beragama non muslim (Kristen dan Katholik) mendapatkan informasi mengenai kesehatan reproduksi secara umum dari pihak gereja berupa bimbingan pra pernikahan. Oleh karena itu, mereka biasanya mencari informasi dengan teman sebaya dan melalui aplikasi di ponsel mereka.

Menurut Ibu Maria, selaku kepala Puskesmas Kenarilang, mengatakan bahwa remaja perempuan sudah tidak seperti yang kita kira sebelumnya.

“... kan mereka punya organ reproduksi, istilahnya (mens) tiap bulan, giliran mereka mau dekat laki-laki tidak direstui oleh orang tua karena masalah belis, iya kalau mereka diajak lari kan tidak diakui keluarga. Tapi misalnya karena perempuan itu lulusan bidan, orang tuanya PNS, kan orang tuanya malu jika putrinya pacaran sama tukang ojek. Iya kan, akhirnya apa? Cinta di belakang saja to. Putus akhirnya tidak kawin-kawin. Perempuan tidak ada yang melamar, sedangkan pacarnya tidak berani melamar karena persyaratan belis yang mahal, membuat mereka tidak sanggup." (Ibu Ma, Puskesmas Kenarilang, 29 Maret 2018)

Perempuan di Kabupaten Alor banyak mengalami dilema dalam hidup di Alor. Budaya dan hukum Adat masih kuat sehingga mereka, seperti tidak sanggup untuk tidak patuh terhadap aturan adat tersebut, khususnya mengenai belis (mas kawin) yang harus diberikan oleh pihak laki-laki kepada pihak perempuan.

Namun, program sosialisasi dari pemerintah dapat berjalan lancar dan sukses di Provinsi NTT, salah satu program kesehatan yang ditujukan pada remaja adalah pemilihan Duta Genre. Saat itu pada pemilihan Duta Genre, Alor berhasil menjuarai di 
tingkat Provinsi NTT dan secara Nasional Juara II pada tahun 2014 dan 2015. Duta Genre ini merupakan remaja terpilih yang bertugas untuk mensosialisakan program kesehatan khususnya kepada remaja di sekitarnya. Mereka bertugas selama masa tertentu. Kepala BKKBN Kabupaten Alor, Bapak Emmanuel, mengatakan:

“... sebenarnya harus sejak dini kita sampaikan tahapan remaja itu kita sudah harus memberikan pemahaman. Pemahaman diharapkan dari rumah atau orang terdekat. Orang itu harus memberikan pemahaman untuk itu, di samping nanti juga di sekolah lewat Pusat Informasi Konseling (PIK). Secara berkala instansi kesehatan juga sekolah memberikan sosialisasi-sosialisasi tersebut. Karena memang temanteman di lapangan itu juga bahan untuk mereka sosialisasi kepada masyarakat" (Bapak Em, BKKBN, Di Kupang, 27 Maret 2018)

Hal ini dibenarkan oleh Mama Yuliana, seorang Pendeta di Kalabahi,

“... kalau di lingkungan sini di kasih tahu kan kalau kamu payudara sudah mulai tumbuh, kamu sudah dapat haid. Di dikasih tahu gitu. Mereka dapat informasi itu dari orang tua. Jadi tidak ditutupi. Apalagi sekarang kan ada informasi di TV tentang pembalut dan segala macam, biasanya timbul pertanyaan dari anak kecilnya. "Mama ini kok ada pembalut?" "kamu masih kecil tapi suatu saat kamu akan memakainya, caranya begini". (Mama Yu, Kalabahi, 29 Maret 2018)

Di Kabupaten Alor semua pihak berperan dalam memberikan informasi mengenai kesehatan reproduksi mulai dari ibu, kakak, dan semua anak-anak dari sekolah, dan yang penting terdapat dalam mata pelajaran di sekolah mengenai informasi kesehatan reproduksi harus ditingkatkan tanpa rasa malu. Perempuan berhak mendapatkan informasi seluas-luasnya karena kesehatan reproduksi itu mulai dari menstruasi pertama sampai lansia pun itu kesehatan reproduksi, jadi harus mendapatkan perlakuan yang baik. Selama ini mereka belum mengerti dan mendapatkan informasi mengenai hak kesehatan reproduksi. Selama ini para wanita usia subur baru mendapatkan informasi mengenai kesehatan reproduksi dari bidan, posyandu, buku KIA atau brosur yang diperoleh dari puskesmas.

Pilihan untuk menggunakan alat kontrasepsi dibicarakan antara suami istri. Selama ini partisipasi suami untuk berpartisipasi mengikuti keluarga berencana masih rendah, mereka tidak mau berpartisipasi terutama vasektomi karena takut efek sampingnya, sebagai kepala rumah tangga mereka khawatir mendapatkan dampak atau pengaruh dari KB. Pilihan yang berpartisipasi dalam ber-KB adalah perempuan, selain karena tidak mau repot akibat banyak anak, juga kesadaran mengenai masalah kesehatan akibat banyak anak. 
Hak yang berkaitan dengan kesehatan reproduksi antara lain keinginan tidak ingin melakukan hubungan intim dengan suaminya pada perempuan Alor tidak mungkin diperoleh. Bagi mereka jika menolak keinginan suami untuk melakukan hubungan intim maka akibatnya adalah menerima perlakuan kurang baik dari suami, antara lain pukulan. Hal ini tidak lepas dengan masih kuatnya masalah adat/budaya mengenai posisi perempuan di Alor.

Nilai anak laki-laki bagi masyarakat Alor lebih tinggi daripada anak perempuan, sebab laki-laki adalah penerus keturunan keluarganya, meskipun anak perempuan akan bisa memperoleh nilai 'belis' yang tinggi, sesuai dengan kedudukan keluarga atau pertimbangan tertentu (pendidikan perempuan, pekerjaan dan lain lain). Namun demikian setelah perempuan itu diberi belis, maka terjadilah pukul 'moko' artinya perempuan tersebut akan 'kawin masuk' dan jadi milik keluarga suami dan hilanglah semua hak perempuan tersebut.

Oleh karena itu jika salah satu keluarga belum mempunyai anak laki-laki, maka mereka kan berusaha mendapatkan anak laki-laki, bahkan jika harus kawin lagi demi mendapatkan anak laki-laki meskipun secara gereja seorang suami tidak boleh kawin lagi, tapi mereka akan kawin secara adat demi mendapatkan seorang anak laki-laki, dan si istrinya tidak boleh melarangnya.

Perempuan usia subur dan remaja sebagai bagian dari vulnerable group masih kurang diperhatikan. Masyarakat yang tinggal di pemukiman padat dan minim pendidikan. Masyarakat ini biasanya menggantungkan kepada alam sebagai aktivitas ekonominya. Masyarakat ini dapat digolongkan pada vulnerable group. Mereka tidak dapat mengakses pendidikan secara bagus, karena kelompok ini hanya berfokus pada aktivitas ekonomi sehari-hari. Mereka biasanya bekerja sebagai nelayan, petani dengan ladang kecil, serta sektor jasa seperti tukang ojek atau sopir angkot. Aktivitas ekonomi ini menghasilkan pendapatan yang pas-pasan sehingga mereka sangat susah untuk membayar belis (moko) walaupun sudah menikah lama.

Gambaran ekstrem terkait masalah harga belis yang tinggi, ada beberapa keluarga yang telah mempunyai keturunan, sampai sekarang belum memiliki akte nikah karena belum beli belis. Kemudian masyarakat adat, pemerintah, dan pemuka agama menggelar pernikahan massal dengan kesepakatan nilai harga moko yang setara, ada pasangan kakek-nenek yang menikah di acara itu bersama dengan cucunya juga. 
Di Kabupaten Alor berkaitan dengan masalah kuatnya tradisi, sejak beberapa tahun terakhir World Vision Indonesia (WVI) terakhir fokus membantu dalam mencari jalan tengah terbaik terkait belis (mas kawin) ini. Dalam salah satu dialog bersama masyarakat dengan perwakilan dari adat per rumpun suku tercetus pemikiran untuk mencari jalan tengah terkait belis tanpa menghilangkan budaya ini. Maka dibuatlah kerja sama dengan Badan Pemberdayaan Masyarakat dan Desa (BPMD) dan pemerintah Kabupaten Alor untuk membuat Undang-Undang (UU) yang nantinya disahkan menjadi peraturan bupati. Sejauh ini WVI dan BPMD telah menunggu sidang dari DPRD Kabupaten Alor untuk mensahkan peraturan bupati tentang jumlah belis dalam proses pernikahan masyarakat di Alor.

Dari perbincangan dan intervensi WVI, tercetuslah ide untuk melakukan sebuah revitalisasi budaya, yakni penyederhanaan prosesi adat pernikahan dan biaya belis. Harapannya, hal ini secara perlahan mengurangi masalah-masalah di masyarakat tadi. Setelah menggelar beberapa dialog dengan tokoh masyarakat, ketua adat, dan pemerintahan. Pada tahun 2012 tercipta sebuah aturan (disebut mal) baru di masyarakat adat untuk mengambil kesepakatan harga moko yang sama dan setara di 12 rumpun suku. Harganya yakni sebesar Rp 7.000.000 dengan pertimbangan simbol religi dan jumlah simbol pertukaran di awal penggunaan moko (sebesar 150 perak uang Belanda, dan disamakan nilainya dengan nilai rupiah sekarang). namun faktanya sampai sekarang banyak warga yang masih meminta biaya belis (moko) dengan harga tinggi.

Hak yang berkaitan dengan kesehatan reproduksi antara lain keinginan tidak ingin melakukan hubungan intim dengan suaminya pada perempuan Alor tidak mungkin diperoleh. Bagi mereka jika menolak keinginan suami untuk melakukan hubungan intim maka akibatnya adalah menerima perlakuan kurang baik dari suami, antara lain pukulan. Hal ini tidak lepas dengan masih kuatnya masalah adat/budaya mengenai posisi perempuan di Alor. 


\section{PENUTUP}

Permasalahan mengenai akses perempuan terhadap pelayanan kesehatan reproduksi tidak bisa dilepaskan dari konteks sosial budaya masyarakatnya. Dalam sistem patriarki perempuan tergantung pada laki-laki dalam hal pengambilan keputusan untuk mengakses pelayanan kesehatan reproduksi. Hal ini menjadi hambatan utama yang harus dihadapi oleh perempuan dalam mengakses layanan kesehatan reproduksi. Hambatan ini tidak hanya dilihat melalui dari sudut pandang masyarakatnya tetapi juga melihat kondisi ekonomi dan wilayah geografis wilayahnya.

Saran yang bisa disampaikan yaitu tradisi penyerahan belis-moko dalam perkawinan agar tetap dijaga, untuk menjaga kelestarian moko. Selain itu, pemerintah daerah dan para tetua adat perlu bekerja sama untuk mengawasi agar tidak terjadi kesewenang-wenangan dalam penentuan harga atau nilai moko. Perlu juga adanya sosialisasi pada masyarakat tentang arti penting moko sebagai warisan budaya dan identitas Alor yang wajib dilestarikan namun setidaknya lebih kompromis dan mengikuti perkembangan jaman. Hal ini agar tidak memberatkan dan menjadi beban masyarakat Alor yang berkepanjangan.

\section{REFERENSI}

Bazeley, Patricia. 2007. Qualitative Data Analysis: Practical Strategies. Sage Publications Ltd.

Dinas Kesehatan Provinsi (Provincial Health office) Nusa Tenggara Timur. 2012. Profil Kesehatan Provinsi NTT, Tahun 2011 [the 2011 Health Profile of NTT Province]. Revised Edition

Finlayson K. and Downe S. 2013. Why Do Women Not Use Antenatal Services in Low-and Middle-Income Countries? A Meta-Synthesis of Qualitative Studies. PLoS Medicine, 10(1): e1001373. doi:10.1371/journal.pmed.1001373

Ministry of Health. 2010. The 2007 Public Health Development Index [Indeks Pembangunan Kesehatan Masyarakat Tahun 2007] Badan Penelitian dan Pengembangan Kesehatan. Jakarta.

Ministry of Health. 2015. Petunjuk Teknis Pelaksanaan Kesehatan Reproduksi Terpadu di Tingkat Pelayanan Dasar. Jakarta: Kementerian Kesehatan.

Ministry of Health. 2014. Peraturan Pemerintah Nomor 61 Tahun 2014 Tentang Kesehatan Reproduksi. Jakarta: Kementerian Kesehatan.

Ministry of Health and UNFPA. 2015. Pedoman Teknis: Pemantauan Pencapaian Akses Universal Kesehatan Reproduksi. Jakarta: Kementerian Kesehatan and UNFPA.

Pardosi JF; Adair T; Rao C; Kosen S; Tarigan IU. 2014. "Measuring subnational under-5 mortality: Lessons from a survey in the eastern Indonesian district of Ende". AsiaPacific Journal of Public Health, vol. 26, no. 4, pp. 367 - 377, http://dx.doi.org/10.1177/1010539511427176 
Pardosi JF; Parr N; Muhidin S. 2015. “Inequity Issues And Mothers' Pregnancy, Delivery And Early- Age Survival Experiences In Ende District, Indonesia". Journal of Biosocial Science, vol. 47, no. 6, pp. 780 - 802, http://dx.doi.org/10.1017/S0021932014000522

Pardosi JF; Parr N; Muhidin S. 2017. "Fathers and infant health and survival in Ende, a rural district of Eastern Indonesia". Journal of Population Research, pp. 1 - 23, http://dx.doi.org/10.1007/s12546-017-9183-6

Pardosi JF; Parr N; Muhidin S. 2017. "Local government and community leaders' perspectives on child health and mortality and inequity issues in rural eastern Indonesia". Journal of Biosocial Science, vol. 49, pp. 123 - 146, http://dx.doi.org/10.1017/S0021932016000134

Piane, Gina Marie. 2009. "Evidence-based practices to reduce maternal mortality: a systematic review". Journal of Public Health, 31(1): 26-31. doi: 10.1093/pubmed/fdn074

Prasodjo R; Musadad DA; Muhidin S; Pardosi JF; Silalahi M. 2015. “Advocate Program for Healthy Traditional Houses,, in a Timor Community: Preserving Traditional Behavior and Promoting Improved Health Outcomes". Journal of Health Communication: international perspectives, vol. 20, no. sup1, pp. 10 - 19, http://dx.doi.org/10.1080/10810730.2015.1013390

Prasodjo R; Musadad DA; Muhidin S; Pardosi JF; Silalahi M. 2015. “Advocate Program for Healthy Traditional Houses,, in a Timor Community: Preserving Traditional Behavior and Promoting Improved Health Outcomes", Journal of Health Communication: international perspectives, vol. 20, no. sup1, pp. 10 - 19, http://dx.doi.org/10.1080/10810730.2015.1013390

Prasodjo, R. and Musadad, A. 2003. "Decision making pattern of maternal health care in East Nusa Tenggara Province”. in Indonesian Health Ecology Journal. Vol.2. No.1. April 2003. Jakarta.

Prasodjo, R. et.al. 2009. "Qualitative Study on Avian Influenza in Indonesia" in Regional Health Forum. WHO-South East Asia Region. Vol. 13. No.1, 2009. India.

Prasodjo, R. et.al. 2006. "Women and Child Health and Malaria in Papua (Keerom and Merauke) a Qualitative Study (KAP)" in Buletin Penelitian Kesehatan. Vol.34. No.2. Jakarta.

Ronsmans C., Graham WJ. 2006. "Maternal survival series steering group: Maternal mortality: who, when, where, and why" Lancet, 368(9542): 1189-1200.

Ronsmans, C. Scott, S., Qomariyah, SN., Achadi, E., Braunholtz, D., Marshall, T., Pambudi, E., Witten, KH., and Grahamc WJ. 2009. "Professional assistance during birth and maternal mortality in two Indonesian districts". Bulletin of World Health Organisation [online], 87(6): 416-423.

Statistics Indonesia and Macro International. 2008. "Indonesia Demographic and Health Survey 2007". Calverton, Maryland, USA: BPS and Macro International.

Stewart, DW., Shamdasani, PN., and Rook, DW. 2007. Focus Groups: Theory and Practice, 2nd edition. Sage: Thousand Oaks, CA.

Thaddeus Sand, Maine D. 1994. "Too far to walk: maternal mortality in context". Social Science \& Medicine, 38(8): 1091-1110.

Titaley, Christiana R., Dibley, Michael J., and Roberts, Christine L. 2010. "Factors associated with underutilization of antenatal care services in Indonesia: results of Indonesia Demographic and Health Survey 2002/2003 and 2007". BMC Public Health 2010 10:485. 
Titaley, Christiana R., Hunter, Cynthia L, Dibley, Michael J., and Heywood, Peter. 2010. "Why do some women still prefer traditional birth attendants and home delivery? A qualitative study on delivery care services in West Java Province, Indonesia". BMC Pregnancy and Childbirth, 10:43.

Titaley, Christiana R., Hunter, Cynthia L., Heywood, Peter and Dibley, Michael J. 2010. "Why don't some women attend antenatal and postnatal care services? A qualitative study of community members' perspectives in Garut, Sukabumi and Ciamis districts of West Java Province, Indonesia". BMC Pregnancy and Childbirth, 10:61. 